\title{
Demir Cevheri Analizleri İçin Referans Malzeme Üretim Sürecinde Toplam Demir (Fe) Miktarı Tayini Metot Validasyon Ve Ölçüm Belirsizliğinin Tahmin Edilmesi
}

\section{Method Validation and Estimation of Measurement Uncertainty of Determination of Total Iron (Fe) Content in the Reference Material Production Process for Iron Ore Analyses}

\author{
Fatih Turan $1^{*}(\mathbb{D}$, Sezai Şen 2 (1) \\ ${ }^{1}$ Dokuz Eylül Üniversitesi Mühendislik Fakültesi Maden Mühendisliği Bölümü, İzmir, TÜRKiYE \\ ${ }^{2}$ Dokuz Eylül Üniversitesi Mühendislik Fakültesi Maden Mühendisliği Bölümü, İzmir, TÜRKIYE \\ Sorumlu Yazar / Corresponding Author* : fatih.turan@deu.edu.tr
}

\author{
Gelis Tarihi / Received: 23.08.2021_Arastirma Makalesi/Research Article \\ Kabul Tarihi / Accepted: 23.09.2021 DOI:10.21205/deufmd.2022247013 \\ Atıfsekli/How to cite: TURAN, F, ȘEN, S.(2022).Demir Cevheri Analizleri İçin Referans Malzeme Üretim Sürecinde Toplam Demir (Fe) Miktarı \\ Tayini Metot Validasyon Ve Ölçüm Belirsizliğinin Tahmin Edilmesi. DEUFMD, 24(70), 133-142.
}

$\ddot{0} \mathbf{z}$

ISO 17025 standardına göre, deney sonuçlarının geçerliliğinin güvence altına alınması için yetkin üreticiler tarafından üretilen sertifikalı referans malzeme (CRM) kullanımı gerekmektedir. Cevher referans malzemeleri, üretimi yapılan cevherler için gerçekleştirilen kalite kontrol çalışmalarında, kalibrasyon, metot geliștirme, metot validasyonu, metrolojik izlenebilirlik sağlama, analist ya da cihazın performansının ölçülmesi gibi birçok farklı amaç için kullanılabilen, matris yapıda, belirli özelliklere göre kararlı ve homojen malzemelerdir.

Ülkemizin sahip olduğu demir rezervleri, hammadde ve buna bağlı uç ürünlerin üretimi açısından dünya piyasasındaki rekabet ortamında büyük bir öneme sahiptir. Söz konusu cevherlere uygulanan kalite kontrol testlerinde, ölçüm sonuçlarının doğruluğunun arttırılması ve güvenilirliğinin sağlanması amacıyla akredite laboratuvarlar tarafından analizler gerçekleştirilmektedir.

Bu çalışmada, TS EN ISO 17034: Referans malzeme üreticilerinin yeterliliği için genel şartlar standardı çerçevesinde, ülkemiz demir cevherlerinden üretilecek olan Sertifikalı Referans Malzeme (CRM) için gerçekleștirilmesi düşünülen metot validasyon aşamaları incelenmiştir. DEÜ Maden Mühendisliği Bölümü Kimya Laboratuvarı'nda yapılan analiz yönteminin valide edilmesi ve yapısında yüksek demir $(\mathrm{Fe})$ bulunan demir cevheri ve konsantrelerinde ölçüm belirsizliğinin tahmin edilmesi amaçlanmaktadır.

Anahtar Kelimeler: Akreditasyon, Demir Cevheri, Metot Validasyon ve Ölçüm Belirsizliği 


\section{Abstract}

According to the ISO 17025 standard, the use of certified reference material (CRM) produced by competent manufacturers is required to ensure the validity of the test results. Ore reference materials are stable and homogeneous materials in matrix structure according to certain properties, which can be used for many different purposes such as calibration, method development, method validation, metrological traceability, measurement of analyst or device performance in quality control studies for the ores produced.

The iron reserves of our country have a great importance in the competitive environment in the world market in terms of the production of raw materials and related end products. In the quality control tests applied to the said ores, analyzes are carried out by accredited laboratories in order to increase the accuracy and reliability of the measurement results.

In this study, within the framework of TS EN ISO 17034: General requirements for the competence of reference material producers", the method validation stages that are thought to be carried out for the Certified Reference Material (CRM) to be produced from the iron ores of our country were examined. It is aimed to validate the analysis method and to estimate the measurement uncertainty in iron ore and concentrates containing high iron (Fe) in their structure, carried out in the Chemistry Laboratory of the DEU Mining Engineering Department.

Keywords: Accreditation, Iron ore, Method Validation and Measurement Uncertainty

\section{Giriş}

Akreditasyon, ölçüm hizmeti veren laboratuvarların; deney, kalibrasyon, inceleme ve belgelendirme ișlemlerini yapan uygunluk değerlendirme kuruluşlarının ulusal yada uluslararası kuruluşlar tarafından güvenilirliğinin tescil edilmesidir. TS EN ISO 17025:2017 standardına göre Metrolojik İzlenebilirlik, ölçüm sonuçlarının, her biri ölçüm belirsizliğine katkıda bulunan verilerin dökümate edilmiș kesintisiz bir kalibrasyon zinciri vasitasiyla uygun bir referansa bağlanması olarak tanımlamış ve ilgili standardın 6.5 maddesinde gereksinimleri belirtmiştir [1].

Standardın 6.5.2 maddesinde ise laboratuvarların elde ettiği ölçüm sonuçlarının Uluslararası Birimler Sistemine (SI) göre izlenebilir olmasını, SI'ya metrolojik izlenebilirliği beyan edilmiş yetkin bir üretici tarafından tedarik edilen sertifikalı referans malzemelerin sertifika değerini ile sağlanabileceğinden bahsedilmektedir.

Sertifikalı referans malzeme üretimi, TS EN ISO 17034: Referans malzeme üreticilerinin yeterliliği için genel şartlar" standardı çervesinde gerçekleştirilmelidir. Söz konusu standarda göre üretim aşamalarında ise TS EN ISO/IEC 17025 standardının gereklilikleri sağlanmalıdır. Maden yatağının demir tenörünün tespiti, demir zenginleştirme proses kontrolü, konsantre cevher satışı, demir cevheri ithalat ve ihracatı olmak üzere, demir cevherlerinin üretiminden satıșına kadar tüm aşamalarda yapılacak analizler için yukarıda belirtilen amaçlar doğrultusunda ve TS EN ISO/IEC 17025 Akreditasyonu rehberliğinde, Kalay II Klorür indirgemesinden sonra titrasyon yöntemiyle demir cevherlerinde toplam demir $(\mathrm{Fe})$ tayini metot validasyon ve ölçüm belirsizliği raporu oluşturulmuştur $[1,2,3]$.

\section{Materyal ve Metot}

Kimyasal analiz ișlemlerinde numuneler üzerinde uygulanmasına karar verilen bir metodun kullanılmasından önce, metodun amaca uygun olduğu ve istenilen performansı gösterdiğinin kanıtlanması gerekmektedir. Metodun geçerli kılınması ve doğrulanması için izlenmesi gereken prosedür Şekil 1'de verilmiștir [1,4]. 
DEÜ FMD 24(70), 133-142, 2022

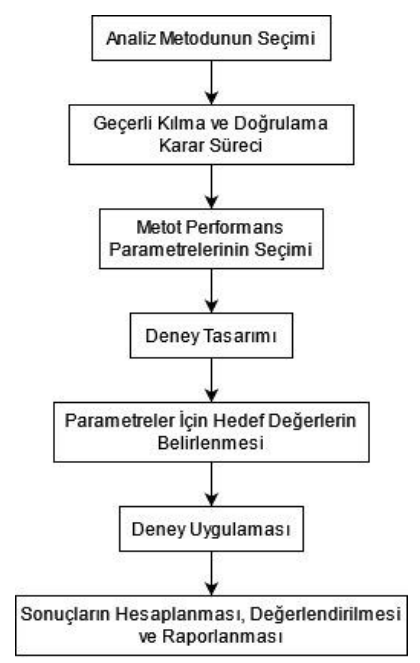

Şekil 1. Metot validasyonu proses akım șeması [4]

Bu çalışmada, Fe analizi işlemlerinde izlenecek yöntem "Kalay II Klorür indirgemesinden sonra titrasyon yöntemiyle demir cevherlerinde toplam Demir (Fe) tayini metodu" olarak belirlenmiştir. Söz konusu yöntemin amaçlanan hedef doğrultusunda kullanılabilirliği değerlendirilerek, doğrulama ve geçerli kılma karar sürecinden sonra performans parametreleri; Homojenlik, Doğruluk, Tekrarlanabilirlik, Tekrarüretilebilirlik, Gerçeklik (Geri Kazanım), LOD (Algılama limiti) ve LOQ (Tayin limiti) olarak belirlenmiş ve tek bir analit (Toplam Fe) analizi yapılacağından basit tekrarlı deneysel tasarım oluşturulmuştur [5].

Yapılan çalışma kapsamında uygulanan deney planı, metodun uygulanması esnasinda sapma yaratabilecek değişkenler (personel, ekipman, sarf malzemesi, zaman) dikkate alınarak oluşturulmuştur. Oluşturulan deneysel tasarım doğrultusunda, performans parametreleri incelenmiş ve sonuçlar kaydedilmiştir. Çalışma tamamlandıktan sonra her bir performans parametresi ayrı başlıklar altında değerlendirilmiştir.

Deneylerde, OREAS 405 Demir Cevheri Sertifikalı Referans Malzemesi kullanılmış ve hedef değerler CRM'nin \%Fe alt ve üst değerleri olarak belirlenmiștir. Deney süreçlerinin tamamı, Dokuz Eylül Üniversitesi Maden Mühendisliği Bölümü Kimya laboratuvarı bünyesinde gerçekleştirilmiştir. Kullanılan malzeme tane boyutu 100 mikron altındadır ve
$105{ }^{\circ} \mathrm{C}$ sicaklıkta 2 saat kurutulduktan sonra analiz işlemlerinde kullanılmıştır.

Numuneden yaklaşık 0,2 g \pm 0,1 mg hassasiyette tartılarak mikrodalga çözme sisteminde; $5 \mathrm{~mL}$ saf su, $10 \mathrm{~mL}$ Hidroklorik Asit $(\mathrm{HCl})(37 \%)$ ve $5 \mathrm{~mL}$ Hidroflorik Asit (HF) (40\%) ile çözünmesi sağlanmıştır. Mikrodalga cihazı çalıșma koşulları; 900-1800 W güç, $200^{\circ} \mathrm{C}$ sıcaklığa $15 \mathrm{dk}$ yükselme ve $15 \mathrm{dk}$ sıcaklığı sabit tutma olacak şekilde ayarlanmıștır. Çözündürme işlemi sonrasında soğuyan çözelti $250 \mathrm{~mL}$ hacimli cam behere aktarılmış ve yaklaşık $50 \mathrm{~mL}$ saf su ile seyreltilmiştir. Nihai çözelti içerisine $30 \mathrm{~mL}$ derişik $\mathrm{HCl}$ (37\%) çözeltisi ilave edilerek $10 \mathrm{dk}$ kaynatılmış, kaynama noktasından soğutulan çözelti potasyum dikromat titrasyonuna tabi tutulmuştur.

Potasyum dikromat titrasyonunda, $250 \mathrm{~mL}$ hacimli beherde bulunan çözeltiye, manyetik karıştırıcı üzerinde manyetik bar ile orta şiddette karıştırılarak, sarı renk kayboluncaya kadar damla damla kalay (II) klorür (\%10’luk) çözeltisi ilave edilmiştir. Renksiz çözelti gözlendikten sonra 2 damla daha kalay (II) klorür ilave edilerek hızlı bir şekilde $20 \mathrm{~mL}$ civa (II) klorür (\%5'lik) çözeltisi eklenmiştir. Kalomel oluştuktan sonra numune $5 \mathrm{dk}$ kadar dinlenmeye alınmıștır. Ardından numune karıștırılarak $20 \mathrm{~mL}$ asit karıșımı $(300 \mathrm{~mL}$ \%98'lik $\mathrm{H}_{2} \mathrm{SO}_{4}, 300 \mathrm{~mL}$ derişik $\mathrm{H}_{3} \mathrm{PO}_{4}$ (85\%), 400 $\mathrm{mL}$ saf su) eklenmiştir. Numuneye, baryum difenilamin sülfonat (\%1) indikatörlüğünde potasyum dikromat $\left(\mathrm{K}_{2} \mathrm{Cr}_{2} \mathrm{O}_{7}\right)(4,9 \mathrm{~g} / 1 \mathrm{~L}, 0,05 \mathrm{~N})$ titrasyonu gerçekleștirilmiştir. Titrasyon sırasında yeșil renkli çözelti mor renge döndüğü anda titrasyon sonlandırılarak potasyum dikromat sarfiyatı kaydedilmiștir. Potasyum dikromat $\left(\mathrm{K}_{2} \mathrm{Cr}_{2} \mathrm{O}_{7}\right)$ faktörünün belirlenmesi amaciyla $0,1 \mathrm{mg}$ hassasiyette $0,8 \mathrm{~g}$ demir amonyum sülfat $\left(\mathrm{H}_{8} \mathrm{FeN}_{2} \mathrm{O}_{8} \mathrm{~S}_{2} * 6 \mathrm{H}_{2} \mathrm{O}\right)$ tartılarak $30 \mathrm{~mL}$ saf su ve $15 \mathrm{~mL} \mathrm{HCl} \mathrm{(37 \% )} \mathrm{ile} \mathrm{birlikte}$ erlen içerisinde çözünmesi sağlanmıştır. Potasyum dikromat titrasyonunda belirtilen şekilde titrasyon işlemi gerçekleştirilerek sarfiyat kaydedilmiştir.

Hesaplama işlemleri,

$$
\% F e=\frac{S x 0,0055847 x 100 x F}{m}
$$

\section{S: Potasyum Dikromat Sarfiyatı \\ m: Numunenin Kütlesi}

F: Potasyum Dikromat Çözeltisi Faktörü 


$$
F=\frac{m * 25,502466}{S}
$$

F: Potasyum Dikromat Çözeltisi Faktörü

S: Potasyum Dikromat Sarfiyatı

m: Demir Amonyum Sülfat Kütlesi

kullanılarak gerçekleştirilmiştir.

\section{Metot Validasyonu Calıșmaları}

\subsection{Homojenite}

15.02.2021 tarihinde 2 farklı personel tarafından analizi gerçekleştirilen Oreas 405 CRM, deney talimatında belirtildiği şekilde hazırlanmıș ve Potasyum Dikromat ile aynı gün içerisinde analizi yapılmıştır. Elde edilen sonuçlar karșılaștırılarak 2 farklı laboratuvar personeli tarafından yürütülen analiz çalışmaları sonucunda elde edilen veriler Tablo 1'de sunulmuştur.

Tablo 1. Homojenite çalışması sonuçları

\begin{tabular}{|c|c|c|}
\hline \multicolumn{3}{|c|}{ CRM Değeri: 58,02 \% } \\
\hline \multirow{2}{*}{ Ölçüm No } & Personel 1 & Personel 2 \\
\cline { 2 - 3 } & Fe (\%) & Fe (\%) \\
\hline 1 & 58,30 & 58,54 \\
\hline 2 & 57,70 & 58,65 \\
\hline 3 & 59,32 & 58,25 \\
\hline 4 & 58,69 & 57,89 \\
\hline 5 & 58,03 & 58,39 \\
\hline 6 & 59,03 & 59,33 \\
\hline 7 & 57,94 & 58,24 \\
\hline 8 & 57,97 & 58,29 \\
\hline 9 & 58,18 & 58,75 \\
\hline 10 & 59,82 & 59,48 \\
\hline Ölçüm Sayısı (n) & 10 & 10 \\
\hline Ortalama & 58,49 & 58,58 \\
\hline STDSP & 0,693 & 0,498 \\
\hline RSD & 0,012 & 0,009 \\
\hline
\end{tabular}

\subsection{Kesinlik}

Deneylerden elde edilen ölçüm sonuçlarının, ortalama değer etrafındaki dağılımının ölçüsü olarak kesinlik ifadesi kullanılmaktadır. Ölçüm sonuçlarının birbirine olabildiğince yakın olması beklenir. $\mathrm{Bu}$ çalışmada, kesinlik parametresi; tekrarlanabilirlik ve tekrarüretilebilirlik değerleri üzerinden değerlendirilmiştir.

Kesinlik, standart sapma, bağıl standart sapma, değișim katsayısı cinsinden ifade edilebileceği gibi tekrarlanabilirlik sınırı (r) veya ara kesinlik sınırı (Ri) olarak da ifade edilebilir [4].

Tekrarlanabilirlik standart sapması tekrarlanabilirlik koşulları altında elde edilen deney sonuçlarının standart sapmasıdır [6].

Tekrarlanabilirlik koşulları deney metodunun izin verdiği kadar kısa zaman aralıklarında, aynı cihaz kullanılarak, aynı kiși tarafından, aynı laboratuvarda, özdeş numunelere aynı metodun uygulanmasını ifade eder.

\subsubsection{Tekrarlanabilirlik}

15.02.2021 tarihinde 2 farklı personel tarafından analizi gerçekleştirilen OREAS 405 CRM, deney talimatında belirtildiği şekilde hazırlanmış ve Potasyum Dikromat ile aynı gün içerisinde analizi yapılmıştır. Elde edilen verilerin karşılaştırılması ve uyumlu olduğunu doğrulamak için ANOVA analizi gerçekleştirilmiştir. Uygulanan $\mathrm{F}$ testi ve $\mathrm{T}$ testi sonucunda $\mathrm{F}<\mathrm{F}$ Crt ve $\mathrm{t}<\mathrm{t}$ Crt olarak tespit edilmiştir. Elde edilen sonuçlar kimyasal analiz işlemlerini gerçekleştiren kişilerin ürettiği verilerin birbiri ile uyumlu olduğunu göstermektedir (Tablo1, Tablo 2 ve Tablo 3 ).

Tablo 2. Tekrarlanabilirlik deney verileri ve ANOVA test sonuçları

\begin{tabular}{|c|c|c|c|c|c|c|}
\hline \multicolumn{2}{|c|}{ ANOVA: Tek Etken } & & & & & \\
\hline Gruplar & Say & Toplam & Ortalama & Varyans & & \\
\hline Sütun 1 & 10 & 584,9839 & 58,4984 & 0,4804 & & \\
\hline Sütun 2 & 10 & 585,8100 & 58,5810 & 0,2476 & & \\
\hline Varyans Kaynağı & SS & df & MS & F & P-değeri & F Kritik \\
\hline Gruplar Arasında & 0,0341 & 1 & 0,0341 & 0,0937 & 0,7629 & 4,4139 \\
\hline Gruplar İçinde & 6,5527 & 18 & 0,3640 & & & \\
\hline Toplam & 6,5868 & 19 & & & & \\
\hline
\end{tabular}


Tablo 3. Tekrarlanabilirlik verileri t-test sonuçları

\begin{tabular}{|c|c|c|}
\hline \multicolumn{3}{|c|}{ t-Test: Ortalamalar İçin İki Örnek } \\
\hline & Değişken 1 & Değişken 2 \\
\hline Ortalama & 58,498386 & 58,581000 \\
\hline Varyans & 0,480446 & 0,247632 \\
\hline Gözlem & 10 & 10 \\
\hline Pearson Korelasyonu & 0,487858 & \\
\hline Öngörülen Ortalama Farkl & 0 & \\
\hline df & 9 & \\
\hline t Stat & $-0,417510$ & \\
\hline P(T<=t) tek-uçlu & 0,343044 & \\
\hline t Kritik tek-uçlu & 1,833112 & \\
\hline P(T<=t) iki-uçlu & 0,686088 & \\
\hline t Kritik iki-uçlu & 2,262157 & \\
\hline
\end{tabular}

\subsubsection{Tekrarüretilebilirlik}

16.02.2021 ile 01.03.2021 tarihleri arasında OREAS 405 sertifikalı referans malzemesi 2 farklı laboratuvar personeli tarafından farklı günlerde 10 defa toplam demir analizine tabi tutulmuştur. Kimyasal analiz işlemleri sonucunda elde edilen veriler Tablo 4'te sunulmuștur. Elde edilen verilerin karşılaştırılması ve uyumluluğunun incelenmesi için ANOVA analizi gerçekleștirilmiştir. Uygulanan $\mathrm{F}$ testi ve $\mathrm{T}$ testi sonucunda $\mathrm{F}<\mathrm{F}$ Crt ve $\mathrm{t}<\mathrm{t}$ Crt olarak tespit edilmiştir. Elde edilen sonuçlar farklı günlerde, farklı kişiler tarafından gerçekleștirilen kimyasal analiz işlemleri sonucunda üretilmiş olan verilerin birbiri ile uyumlu olduğunu göstermektedir (Tablo 4, Tablo 5 ve Tablo 6).

Tablo 4. Tekrarüretilebilirlik deney verileri

\begin{tabular}{|c|c|c|}
\hline \multirow{2}{*}{ Ölçüm Tarihi } & Personel 1 & Personel 2 \\
\cline { 2 - 3 } & Fe (\%) & Fe (\%) \\
\hline 16.02 .2021 & 59,69 & 59,40 \\
\hline 17.02 .2021 & 58,41 & 58,65 \\
\hline 18.02 .2021 & 58,42 & 58,99 \\
\hline 19.02 .2021 & 58,32 & 59,62 \\
\hline 22.02 .2021 & 58,87 & 59,30 \\
\hline 23.02 .2021 & 58,13 & 58,18 \\
\hline 24.02 .2021 & 58,50 & 57,81 \\
\hline 25.02 .2021 & 58,76 & 59,24 \\
\hline 26.02 .2021 & 59,71 & 59,56 \\
\hline 01.03 .2021 & 58,12 & 58,26 \\
\hline Ölçüm Sayısı (n) & 10 & 10 \\
\hline Ortalama (X) & 58,69 & 58,90 \\
\hline STDSP & 0,5812 & 0,6382 \\
\hline RSD & 0,0099 & 0,0108 \\
\hline Ortalama Standart Sapma & \multicolumn{2}{|c|}{0,6036} \\
\hline LOD & \multicolumn{2}{|c|}{6,0363} \\
\hline LOQ & \multicolumn{2}{|c}{} \\
\hline
\end{tabular}

Tablo 5. Tekrarüretilebilirlik deney verileri ve ANOVA test sonuçları

\begin{tabular}{|c|c|c|c|c|c|c|}
\hline ANOVA: Tek Etken & & & & & & \\
\hline Gruplar & Say & Toplam & Ortalama & Varyans & & \\
\hline Sütun 1 & 10 & 586,93 & 58,69 & 0,3378 & & \\
\hline Sütun 2 & 10 & 589,01 & 58,90 & 0,4073 & & \\
\hline Varyans Kaynağı & SS & df & MS & F & P-değeri & F ölçütü \\
\hline Gruplar Arasında & 0,2163 & 1 & 0,2163 & 0,5805 & 0,4559 & 4,4138 \\
\hline Gruplar İçinde & 6,7067 & 18 & 0,3725 & & & \\
\hline Toplam & 6,9230 & 19 & & & & \\
\hline
\end{tabular}

Tablo 6. Tekrarüretilebilirlik verileri t-test sonuçları

\begin{tabular}{|c|c|c|}
\hline t-Test: Ortalamalar İçin İki Örnek & & \\
\hline & Değişken 1 & Değişken 2 \\
\hline Ortalama & 58,9010000 & 58,6930000 \\
\hline Varyans & 0,4073655 & 0,3378233 \\
\hline Gözlem & 10 & 10 \\
\hline Pearson Korelasyonu & 0,6060323 & \\
\hline Öngörülen Ortalama Farkl & 0 & \\
\hline df & 9 & \\
\hline t Stat & 1,2098932 & \\
\hline $\mathrm{P}(\mathrm{T}<=\mathrm{t})$ tek-uçlu & 0,1285692 & \\
\hline $\mathrm{t} \mathrm{Kritik} \mathrm{tek-uçlu}$ & 1,8331129 & \\
\hline $\mathrm{P}(\mathrm{T}<=\mathrm{t})$ iki-uçlu & 0,2571384 & \\
\hline $\mathrm{t} \mathrm{Kritik} \mathrm{iki-uçlu}$ & 2,2621571 & \\
\hline & &
\end{tabular}




\subsection{Doğruluk}

\subsubsection{Geri kazanım}

Geri kazanım, doğruluğun nicel olarak ölçüsü olarak tanımlanır. Metodun doğruluk testi için tekrarlanabilirlik çalışmalarından elde edilen sonuçların teorik değere olan geri kazanım değeri hesaplanmıştır. Geri kazanım sonuçları her bir parametre ve konsantrasyon için hesaplanarak Tablo 7'de sunulmuştur.

Elde edilen geri kazanım sonuçları \% 90-110 aralığında olduğundan, sonuçlar uygundur $[7,8]$.

Tablo 7. Geri Kazanım deney sonuçları

\begin{tabular}{|c|c|c|}
\hline \multicolumn{3}{|c|}{ CRM Değeri : 58,02 \% } \\
\hline \multirow{2}{*}{ Ölçüm No } & Personel 1 & Personel 2 \\
\cline { 2 - 3 } & Fe & Fe \\
\cline { 2 - 3 } & Geri Kazanım & Geri Kazanım \\
\hline 1 & 100,48 & 100,90 \\
\hline 2 & 99,46 & 101,09 \\
\hline 3 & 102,24 & 100,40 \\
\hline 4 & 101,15 & 99,78 \\
\hline 5 & 100,01 & 100,64 \\
\hline 6 & 101,74 & 102,26 \\
\hline 7 & 99,87 & 100,38 \\
\hline 8 & 99,92 & 100,47 \\
\hline 9 & 100,27 & 101,26 \\
\hline 10 & 103,11 & 102,52 \\
\hline
\end{tabular}

\subsection{Sağlamlık}

Metot sağlamlı̆̆ için, numunenin etüvdeki kurutma süresi, mikrodalga yakma sisteminde ilave edilen asit miktarları ve mikrodalga yakma ünitesindeki çevrim sayıları irdelenmiştir. Sonuçlar, Tablo 8, 9 ve 10 ile ve Şekil 2, 3 ve 4'te verilmiştir.

\subsubsection{Kurutma Süresi}

Metot sağlamlığının belirlenmesi için ilk olarak numunenin etüv içinde bekleme süreleri değiştirilmiş ve sonuca etkisi incelenmiştir.

Tablo 8. Kurutma süresi - Sağlamlık deney sonuçları

\begin{tabular}{|c|c|c|}
\hline $\begin{array}{c}\text { Kurutma Süresi } \\
\text { (Saat) }\end{array}$ & \% Fe & $\begin{array}{c}\text { Geri } \\
\text { Kazanım }\end{array}$ \\
\hline 1 & 59,48 & 102,52 \\
\hline 2 & 59,69 & 102,88 \\
\hline 3 & 59,50 & 102,55 \\
\hline 4 & 59,55 & 102,64 \\
\hline 5 & 59,27 & 102,15 \\
\hline
\end{tabular}

Metot sağlamlı̆̆ı parametrelerinden kurutma süresinin değiştirilmesi sonucunda, geri kazanım oranları \%102,15 ile \%102,88 arasında hesaplanmıştır. Bu sonuç, kurutma süresinin 1 saat ile 5 saat arasında olmasının, analiz sonucuna bir etkisinin olmadığını göstermiştir.

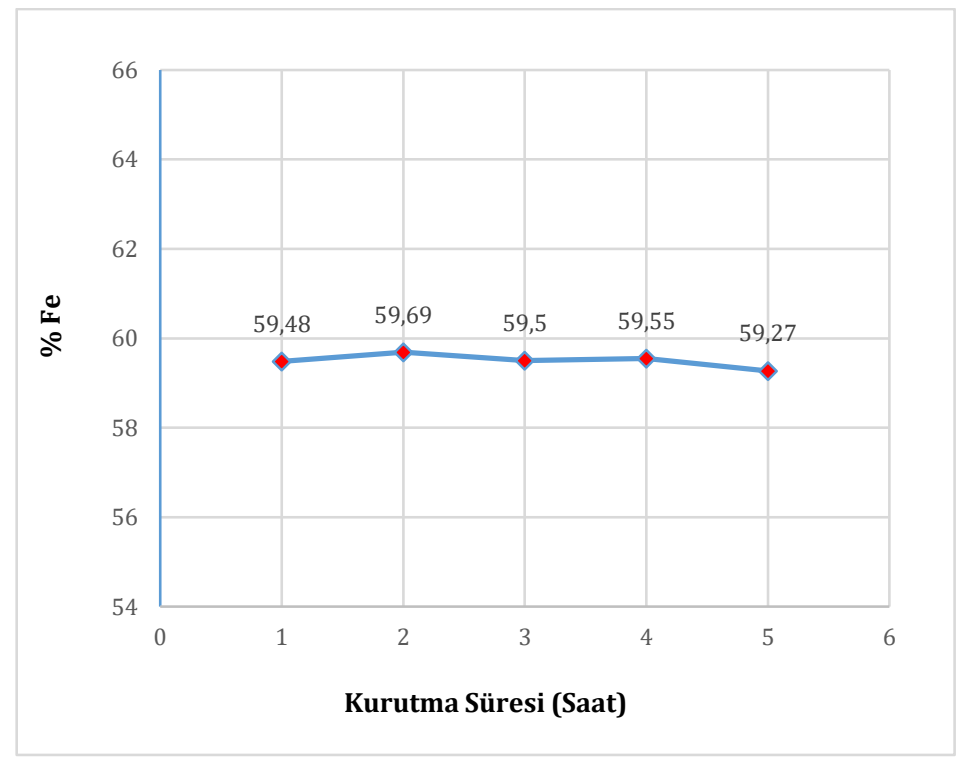

Şekil 2. Sağlamlık (Kurutma süresi) deney sonuçları 


\subsection{2. Çevrim Sayısı (Tur)}

Etüvde $105{ }^{\circ} \mathrm{C}$ 'de 2 saat tutulan CRM 405, mikrodalga yakma ünitesinde her biri 1 tur olarak tanımlanan program çerçevesinde 1800 Watt ve $180^{\circ} \mathrm{C}$ sıcaklıkta, $10 \mathrm{~mL} \mathrm{HCl}(37 \%)$ asit, $5 \mathrm{~mL}$ HF (40\%) ve $5 \mathrm{~mL}$ saf su eklenerek hazırlanmıștır.
Tablo 9. Çevrim sayısı - Sağlamlık deney sonuçları

\begin{tabular}{|c|c|c|}
\hline Çevrim Sayısı & $\% \mathrm{Fe}$ & Geri Kazanım \\
\hline 1 & 58,83 & 101,40 \\
\hline 2 & 58,83 & 101,40 \\
\hline 3 & 57,91 & 99,81 \\
\hline 4 & 59,62 & 102,76 \\
\hline 5 & 58,76 & 101,28 \\
\hline
\end{tabular}

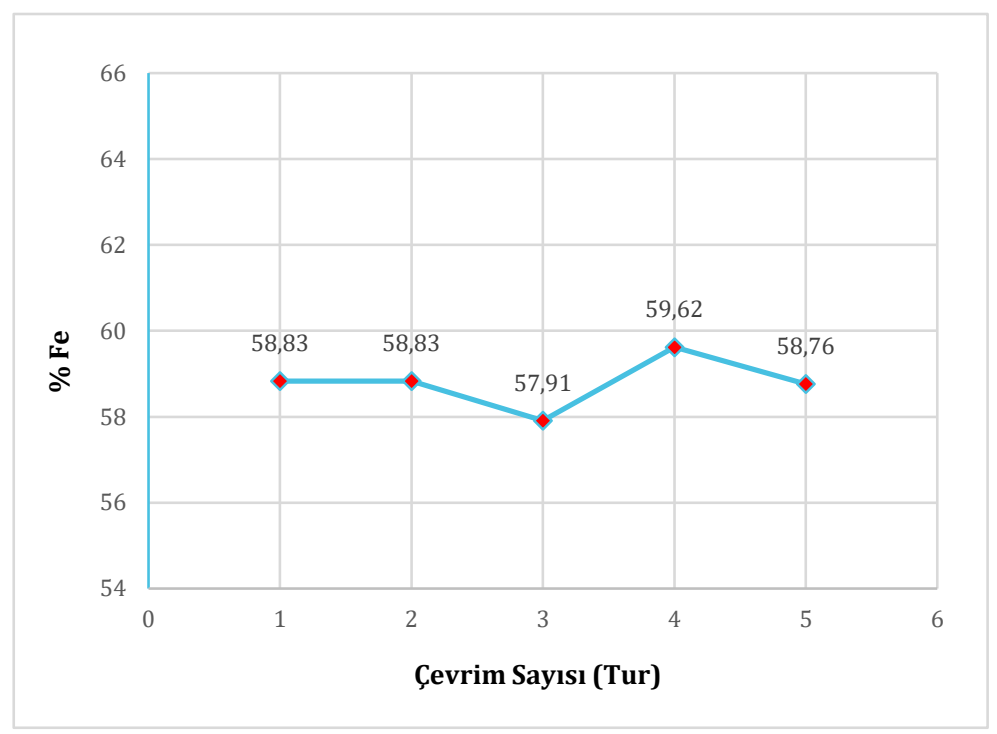

Şekil 3. Sağlamlık (Çevrim sayısı) deney sonuçları

Metot sağlamlığı parametrelerinden mikrodalga yakma ünitesindeki çevrim sayısının (Tur) değiştirilmesi sonucunda, geri kazanım oranları \% 99,81 ile \% 101,40 arasında hesaplanmıștır. $\mathrm{Bu}$ sonuç, çevrim sayısının metot sağlamlı̆̆ noktasında etkin bir parametre olmadığını göstermektedir.

\subsection{3. Çözücü Ortam(HCl) Miktarı}

Etüvde $105^{\circ} \mathrm{C}$ 'de 2 saat tutulan CRM 405 üzerine $5 \mathrm{~mL}$ saf su, $5 \mathrm{~mL} \mathrm{HF}$ (40\%) ve Tablo 10 'da yer alan farklı hacimlerde $\mathrm{HCl}$ (37\%) eklenerek mikrodalga yakma ünitesinde 1 tur olacak şekilde çözünürleştirilmiştir.

Tablo 10. Çözücü ortam ( $\mathrm{HCl})$ miktarı Sağlamlık deney sonuçları

\begin{tabular}{|c|c|c|}
\hline HCl Miktarl $(\mathrm{mL})$ & $\% \mathrm{Fe}$ & Geri Kazanım \\
\hline 5 & 58,81 & 101,36 \\
\hline 10 & 59,37 & 102,33 \\
\hline 15 & 59,54 & 102,62 \\
\hline 20 & 59,59 & 102,71 \\
\hline 25 & 57,88 & 99,76 \\
\hline
\end{tabular}


DEÜ FMD 24(70), 133-142, 2022

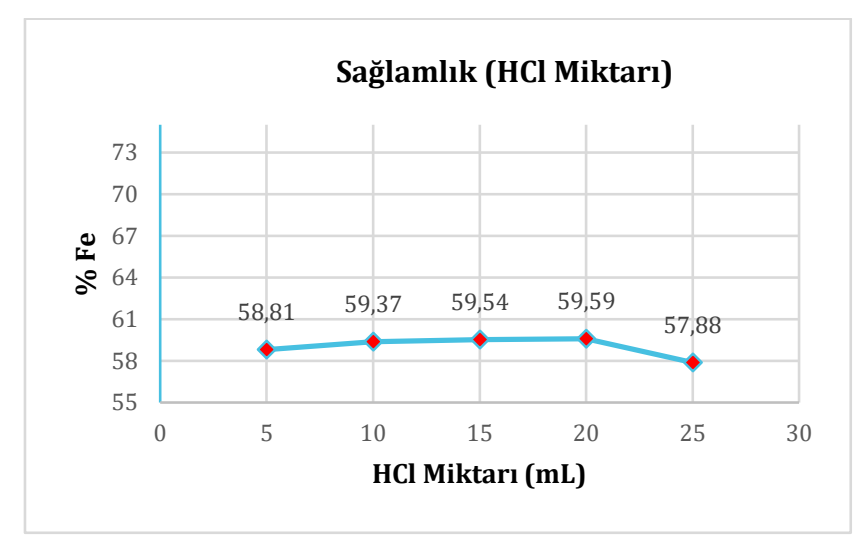

Şekil 4. Sağlamlık (HCl miktarı) deney sonuçları

Metot sağlamlığı parametrelerinden, Hidroklorik Asit ( $\mathrm{HCl})$ miktarının değiştirilmesi sonucunda geri kazanım oranları \% 99,76 ile \% 102,71 arasında hesaplanmıștır. Bu sonuç, $5 \mathrm{~mL}$ ile $25 \mathrm{~mL}$ arasında eklenen asit miktarının, metot sağlamlığı açısından etkin bir parametre olmadığını göstermektedir.

Sağlamlık çalışmalarında, kurutma süresi, mikrodalga yakma ünitesi çevrim sayısı ve $\mathrm{HCl}$ miktarlarındaki değişimler incelenmiş, söz konusu değişikliklerin, geri kazanım açısından fark yaratmadığı görülmüştür.

\section{3. Ölçüm Belirsizliği Bilançosunun Oluşturulması}

DEÜ Maden Mühendisliği Bölümü Kimya laboratuvarı, ölçüm belirsizliği tahmini için, balık kılçığı yöntemini uygulamaktadır $[9,10,11]$.

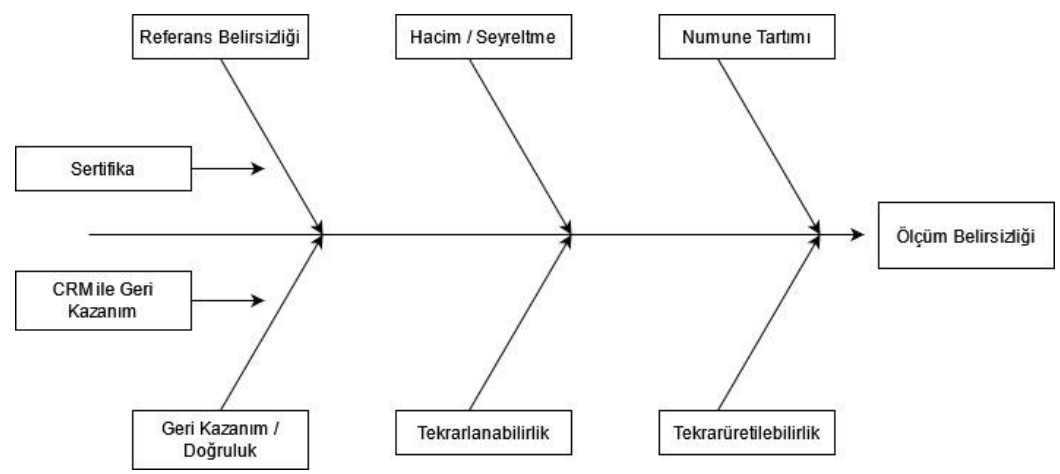

Şekil 5. Ölçüm Belirsizliği için balık kılçı̆̆ı yöntemi

\subsection{Tekrarlanabilirlik}

Tablo 11. Tekrarlanabilirlik - Ölçüm belirsizliği

\begin{tabular}{|c|c|c|}
\hline & Personel 1 & Personel 2 \\
\hline Analiz & Fe \% & Fe \% \\
\hline 1 & 58,30 & 58,54 \\
\hline 2 & 57,70 & 58,65 \\
\hline 3 & 59,32 & 58,25 \\
\hline 4 & 58,69 & 57,89 \\
\hline 5 & 58,03 & 58,39 \\
\hline 6 & 59,03 & 59,33 \\
\hline
\end{tabular}

\begin{tabular}{|c|c|c|}
\hline 7 & 57,94 & 58,24 \\
\hline 8 & 57,97 & 58,29 \\
\hline 9 & 58,18 & 58,75 \\
\hline 10 & 59,82 & 59,48 \\
\hline Ortalama & 58,50 & 58,58 \\
\hline SD & 0,69 & 0,50 \\
\hline SDPool & \multicolumn{2}{|c|}{0,6033} \\
\hline U (X) & \multicolumn{2}{|c|}{0,1349} \\
\hline Rölatif Belirsizlik & \multicolumn{2}{|c|}{0,0023} \\
\hline
\end{tabular}


Balık Kılçı̆̆ı modeli ile tahmini yapılan ölçüm belirsizliğinin ilk girdisi tekrarlanabilirlikten kaynaklanan belirsizliktir. Aynı gün içerisinde 2 analist tarafından yapılan 10 tekrarlı deney sonucunda belirsizlik (U) 0,134914692 olarak hesaplanmıştır.

\subsection{Tekrarüretilebilirlik}

Tablo 12. Tekrarüretilebilirlik - Ölçüm belirsliziği

\begin{tabular}{|c|c|c|}
\hline & Personel 1 & Personel 2 \\
\hline Analiz & Fe \% & Fe $\%$ \\
\hline 1 & 59,69 & 59,4 \\
\hline 2 & 58,41 & 58,65 \\
\hline 3 & 58,42 & 58,99 \\
\hline 4 & 58,32 & 59,62 \\
\hline 5 & 58,87 & 59,3 \\
\hline 6 & 58,13 & 58,18 \\
\hline 7 & 58,5 & 57,81 \\
\hline 8 & 58,76 & 59,24 \\
\hline 9 & 59,71 & 59,56 \\
\hline 10 & 58,12 & 58,26 \\
\hline Ortalama & 58,69 & 58,90 \\
\hline SD & 0,5812 & 0,6382 \\
\hline Sdpool & \multicolumn{2}{|c|}{0,6104} \\
\hline U(X) & \multicolumn{2}{|c|}{0,0023} \\
\hline Rölatif Belirsizlik & \multicolumn{2}{|c|}{} \\
\hline
\end{tabular}

Farklı günlerde 2 analist tarafından gerçekleştirilen analiz işlemlerine göre tekrarüretilebilirlikten elde edilen belirsizlik (U) 0,13649074 olarak hesaplanmıştır.

\subsection{Geri Kazanım}

Gerikazanım değerleri üzerinden yapılan hesaplama sonucu belirsizlik (U) 0,232531355 olarak tespit edilmiștir.

Tablo 13. Geri Kazanım - Ölçüm belirsizliği

\begin{tabular}{|c|c|c|}
\hline & Personel 1 & Personel 2 \\
\hline Analiz & $\mathrm{R}$ & $\mathrm{R}$ \\
\hline 1 & 100,48 & 100,90 \\
\hline 2 & 99,46 & 101,09 \\
\hline 3 & 102,24 & 100,40 \\
\hline 4 & 101,15 & 99,78 \\
\hline 5 & 100,01 & 100,64 \\
\hline 6 & 101,74 & 102,26 \\
\hline 7 & 99,87 & 100,38 \\
\hline 8 & 99,92 & 100,47 \\
\hline 9 & 100,27 & 101,26 \\
\hline 10 & 103,11 & 102,52 \\
\hline Ortalama & 100,82 & 100,97 \\
\hline SD & 1,1946 & 0,8576 \\
\hline Sdpool & \multicolumn{2}{|c|}{1,0399} \\
\hline U(X) & \multicolumn{2}{|c|}{0,002325} \\
\hline Rölatif Belirsizlik & \multicolumn{2}{|c|}{} \\
\hline
\end{tabular}

\subsection{Tartım Belirsizliği}

Tartım cihazı için kalibrasyon sertifikasında 0,2 $\mathrm{g}$ için belirtilen belirsizlik değeri 0,00008'dir.

\subsection{Hacim belirsizliği}

\subsubsection{0 mL Cam Pipet Belirsizliği}

Tablo 14. Cam pipet ölçüm belirsizliği deney verileri

\begin{tabular}{|c|c|}
\hline Deney No & Sonuç, g \\
\hline 1 & 50,0012 \\
\hline 2 & 50,0018 \\
\hline 3 & 50,0014 \\
\hline 4 & 50,0011 \\
\hline 5 & 49,9998 \\
\hline ORT & 50,0011 \\
\hline SD & 0,0007 \\
\hline n & 5 \\
\hline U & 0,0003 \\
\hline Bağll U & $3,37046 \mathrm{E}-05$ \\
\hline
\end{tabular}

5 tekrarlı hacim ölçümleri, saf su kullanılarak hassas terazide kütle ölçülerek gerçekleştirilmiştir. Buna göre belirsizlik (U) 0,000337046 olarak hesaplanmıştır.

\subsubsection{Dijital Büret Belirsizliği}

Dijital büret için alınan hacimler, hassas terazide tartılmış ve sonuçlar kaydedilmiştir. Buna göre dijital büret için belirsizlik (U) 0,02131103 olarak hesaplanmıștır.

Tablo 15.Dijital büret ölçüm belirsizliği deney verileri

\begin{tabular}{|c|c|}
\hline Deney No & Sonuç, $\mathrm{mL}$ \\
\hline 1 & 50,0120 \\
\hline 2 & 50,1000 \\
\hline 3 & 50,0900 \\
\hline 4 & 50,1100 \\
\hline 5 & 50,1400 \\
\hline ORT & 50,0904 \\
\hline SD & 0,0476 \\
\hline n & 5 \\
\hline U & 0,0213 \\
\hline Bağl U & 0,0021 \\
\hline
\end{tabular}




\subsection{Belirsizlik bütçesi}

Tablo 16. Toplam Ölçüm Belirsizliği

\begin{tabular}{|c|c|}
\hline \multicolumn{2}{|c|}{ Belirsizlik Bütçesi } \\
\hline Belirsizlik Kaynakları & Belirsizlik Değeri \\
\hline Tekrarlanabilirlik & 0,00230 \\
\hline Tekrarüretilebilirlik & 0,00232 \\
\hline Geri Kazanım & 0,00230 \\
\hline Terazi Belirsizliği & 0,00008 \\
\hline Hacim Belirsizliği 50 mL cam Pipet & $3,37046 \mathrm{E}-05$ \\
\hline CRM Belirsizliği & 0,00275 \\
\hline Hacim Belirsizliği Dijital Büret & 0,00213 \\
\hline Toplam Belirsizlik & 0,01193 \\
\hline Genişletilmiş Belirsizlik & 0,02386 \\
\hline
\end{tabular}

Belirsizlik kaynaklarından elde edilen sonuçlar toplanarak Toplam Belirsizlik 0,011933207 olarak hesaplanmıștır. \%95 k=2 güven aralığında ise genişletilmiş belirsizlik değeri 0,023866415 olarak tespit edilmiştir.

\section{Tartışma ve Sonuç}

Algılama Limiti: Algılama limitinin hesaplanmasında kullanılan yöntem TEKRARÜRETILEBILIRLIĞIN STANDART SAPMASI'nın 3 katının alınması ile elde edilmektedir. Demir Cevherlerinde Toplam Demir Tayini deneyinde LOD değeri așağıda verilmiştir.

$$
L O D=3 \times s_{0}^{\prime}
$$

Algılama Limiti (LOD) $=\mathbf{1 , 8 1} \%$ olarak tespit edilmiștir.

Tayin Limiti: Alglama limitinin hesaplanmasında kullanılan yöntem TEKRARÜRETILLEBILIRLIĞİIN STANDART SAPMASI'nın 10 katının alınması ile elde edilmektedir. Demir Cevherlerinde Toplam Demir Tayini deneyinde LOQ değeri aşağıda verilmiştir.

$$
L O Q=10 \times s_{0}^{\prime}
$$

Tayin Limiti (LOQ) $=\mathbf{6 , 0 4} \%$ olarak tespit edilmiştir.

Genişletilmiş Ölçüm Belirsizliği; 0,02386 olarak hesaplanmıştır. Ölçüm belirsizliği değeri, analiz sonucu ile çarpılarak elde edilen değer +/ölçüm belirsizliği olarak verilebilmektedir.

Yapılan değerlendirmede Dokuz Eylül Üniversitesi Maden Mühendisliği Bölümü Kimya Laboratuvarında Demir Cevherlerinde Toplam
Demir Tayini parametresinin ölçülebilirliği teyit edilmiştir [12,13,14].

Toplam Demir Tayininde kullanılan yöntemin, Sertifikalı Referans Malzeme özelliklerinin belirlenmesinde kullanılabilir bir analiz metodu olduğu, ayrıca metrolojik izlenebilirlik açısından da SI birim sistemleri ile kesintisiz zincir vasitasıla izlenebilir olacağı değerlendirilmiştir.

\section{KAYNAKLAR}

[1] International Organization for Standardization (ISO), 2017. ISO/IEC 17025 General requirements for the competence of testing and calibration laboratories.

[2] Yılmaz, A., Türklab. Kimyasal Analizlerde Metot Validasyonu ve Verifikasyonu, Rehber 01, İstanbul.

[3] EURACHEM, 2012. EURACHEM / CITAC Guide CG 4 Quantifying Uncertainty in Analytical Measurement (third edition).

[4] Türk Akreditasyon Kurumu (TÜRKAK), 2019. Metodun Geçerli Kılınması ve Doğrulanması için Bilgilendirme Kılavuzu.

[5] Gökçe B., Taşgetiren, S., 2009. Kalite İçin Deney Tasarımı, Makine Teknolojileri Elektronik Dergisi Cilt. 6, s. 71-83.

[6] International Organization for Standardization (ISO), 2006. ISO 3534-1:2006 Statistics Vocabulary and symbols -Part1:General statistical terms and terms used in probability.

[7] AOAC Guidelines for Single-Laboratory Validation of Chemical Methods for Dietary Supplements and Botanicals (current edition) Official Methods of Analysis, Appendix K, AOAC INTERNATIONAL, Rockville, MD, USA

[8] International Organization for Standardization (ISO), 1994. ISO 5725-1: 1994 Accuracy (trueness and precision) of measurement methods and results - Part 1: General principles and definitions. DOI:10.1029/JC095iC10p18303

[9] Türk Akreditasyon Kurumu (TÜRKAK), 2015. R20.02 Deney/Analiz Sonuçlarındaki Ölçüm Belirsizliği Tahmini İçin TÜRKAK Prensipleri.

[10] International Organization for Standardization (ISO), 2017. ISO 21748:2017 Guidance for the use of repeatability, reproducibility and trueness estimates in measurement uncertainty evaluation.

[11] Miller, J. N., Miller, J. C., 2010. Statistics and Chemometrics for Analytical Chemistry Sixth edition. Pearson Education Canada

[12] National Association of Testing Authorities (NATA), 2018. "Validation and verification of quantitative and qualitative test methods", Australia

[13] NMKL - NordVal Internetional, 2009. "Validation of chemical analytical methods", $3^{\text {rd }}$ Ed., Norway.

[14] Thompson, M., Ellison, S. L. R., Wood, R., 2002. Harmonized guidelines for single-laboratory validation of methods of analysis, Pure Appl. Chem., Sayı 74, No. 5, s. 835-855. 